\title{
Performance Analysis Framework Codeigniter and CakePHP in Website Creation
}

\author{
Hustinawati \\ Information System Department \\ Gunadarma University \\ Indonesia
}

\author{
Albert Kurnia Himawan \\ Information System Department \\ Gunadarma University \\ Indonesia
}

\author{
Latifah \\ Information System Department \\ Gunadarma University \\ Indonesia
}

\begin{abstract}
IThe era of rapidly evolving technologies currently provide a positive influence on the development of web technology . One such technology is the development of the framework. Framework is a framework that allows developers to build an application. There are two types of frameworks, one of which is a web application framework. In this framework there is one type of framework that is widely used by web developers, which is a PHP framework that until now has been growing more than fifteen types to follow the progress of existing technology. With the development of web technology, in addition to facilitate can also cause problems both for the beginners in the world of PHP programming or PHP programmers to choose a framework which is more convenient and effective to use. Therefore, in this study will be a comparison between the two types, namely PHP framework CakePHP framework CodeIgniter framework that is implemented with the creation of websites to display data from a database, so that the two kinds of PHP frameworks can be known benefits and drawbacks to the analysis based on six factors namely in terms of performance, architecture, features - features that are available, the application of Ajax, ORM implementation, and capacity of each library - each framework.
\end{abstract}

\section{General Terms}

Web programming

\section{Keywords}

comparative analysis, cakephp, codeIgniter, framework.

\section{INTRODUCTION}

Developments in the field of IT projects currently progressing very rapidly.. This is evidenced by one of the online marketplace site, freelancer.com [1], that the IT projects which have been published in 2012 on the site has reached about four million more. From the number of IT projects shows that the IT project has developed very rapidly. The execution of an IT project will be managed into a project that provides a system solution that is aligned with the objectives that have been established and sufficient to provide the maximum benefit for the company, if the project has a good management. IT project management itself control the three main components, namely time, cost, and functionality . Of the three it can be concluded that how to save time and cost to produce satisfactory results. Therefore, the framework is used to save time in the IT project expands.

Framework is a framework to assist in developing an IT project to deal with issues such as connecting to a database programming and call variables and files. In 2013 , the number of frameworks already consists of more than fifteen types [2]. Among the most frequently used by developers is CodeIgniter and Cake PHP. Seen from companies - big companies like Mozilla add-on as well as the compass that uses both the framework . But to find out which one is better to use in terms of performance, the architecture, the application of the framework to ajax features - supporting features are given respectively - each framework then it should do a comparison. Comparative analysis was conducted on a website that displays employee database table using CakePHP framework as well as websites that display movie data using CodeIgniter framework.

\section{Problem Formulation}

How the results of the comparison between the two frameworks are CakePHP with CodeIgniter views from the 6 factors in terms of performance, architecture, features features that are given, the application of Ajax, ORM implementation, and capacity of each library each framework?

\section{Limitations}

In this paper a comparison will be made only to the two PHP frameworks are Cake PHP and CodeIgniter.

\section{Objectives}

This research aims to:

- Obtain the differences and advantages of CodeIgniter and CakePHP

- Helping novice in the world of PHP programming or PHP programmers who want to have a practical overview of the comparison between CodeIgniter and Cake PHP

\section{THEORETICAL VIEW Framework}

According to the English dictionary - Indonesia [3] which was developed by John M. Echols and Hassan Sadily framework means the framework. Framework called for the work to be performed must follow and not run away from the frame . Framework is a set of libraries that are organized in an architectural design to deliver the speed, accuracy, convenience and consistency in the development of such applications, the framework contains the following elements :

- Architecture

- File library (library )

- Methodology . [ LIB10 ].

If this framework is associated with the word PHP, it can be interpreted as a patterned framework that enables easy web development using PHP language.

Pattern - a common pattern needed to build a web application has been provided by the PHP framework and packed into a 
pattern - a specific pattern called the class . Therefore, by using the PHP framework, just need to add the code - the code logic that will be processed according to the rules of the framework being used.

Some of the advantages of the use of the framework are as follows [ 4]:

- The structure of the application neat and orderly fashion , usually using MVC structure that performs the separation between business logic with presentation.

Save time and money, because they build the application does not start from scratch but only to use a variety of features that exist .

- Possible applications will be more secure and reusable, because the framework is built on the experience of building applications .

- Capable of handling a lot of things with ease, such as templating, database, validation, cache management, and various other features. However there are some drawbacks when using the framework are:

- The programmer will probably find the limitations when designing an application using the framework

- Possible development will add to the cost if the framework is used less documented and less supported.

\section{Framework Cake PHP}

CakePHP is a PHP -based framework that can be used to make large-scale applications. This framework is able to simplify the creation of applications CRUD ( Create, Read, Update, Delete) with character development RAD (Rapid Application Development ).

This framework has several characteristics, such as [5] :

- Using the Model View Controller architecture, with support for object -oriented programming

- Compatible with PHP 4 and PHP 5

- Ability CRUD is supported by the interaction of queries against databases and use tables and associations easily

- Support the use of Ajax, Javascript, HTML Forms, and so on , by using view Helpers

- Making a fast and flexible templates

- Has the handling of Security, Session, and Request Handling

The structure of the work described in accordance with the CakePHP MVC architecture in general where the request of the user described as a task of the controller, which has a lot of method to the request. The controller will take the data in the database through the model . Each model describes each table who is with other relations between tables, and data validation mechanisms that exist in the table. While the View is used to display the data processed by the Controller to the appropriate users layouts that exist in the template page [6] Application of Ajax in CakePHP Helpers done with the help of Ajax and Javascript. CakePHP also requires additional libraries from prototype and script.aculo.us which contains functionality - Ajax core functions and effects for dynamic web. Ajax Helpers contains methods that implement the use of the library.
CodeIgniter

CodeIgniter is a web application framework that is open source used to build dynamic PHP applications. The main purpose is to assist the development of CodeIgniter developers to work on apps faster than writing all the code from scratch . CodeIgniter introduced on February 28, 2006 [ 7 ].

Characteristics of CodeIgniter is as follows: 1) It has the characteristics of flexible and lightweight for ease in learning, modifying, and integrating Library and Helper.

2) Using the MVC pattern so that the structure of the generated code is more structured and have clear standards.

3) produced very friendly URLs. In Code Igniter minimized use \$ _GET and replaced with a URL. The workings of CodeIgniter is as shown in Figure 1.

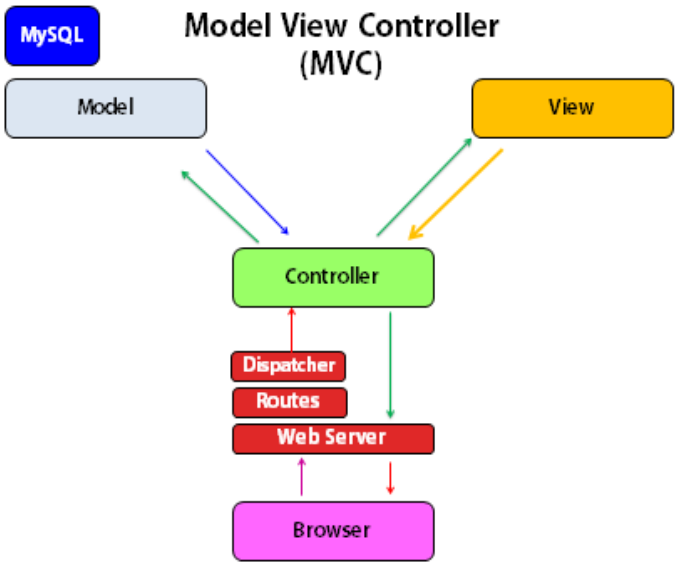

Figure 1. Structural Work CodeEigniter

Structure of CodeIgniter work starts from a browser which will interact via the controller. Then the controller will receive and reply to all requests from the browser. For data, the controller will ask for the model and for the UI / template controller will ask to view. When a browser requests a web page then the router will find the controller which should handle the request . later the controller will use to access the data and the model view to display the data.

MVC is used to separate the data access and business logic from the data presentation and user interaction . Separation was done so that any changes in the presentation logic or business logic does not give effect to each other are complex . MVC separation solution is expected to improve the flexibility and reusability of the application .

The MVC architecture separates applications into three parts , namely Model, View and Controller as shown in Figure 2.

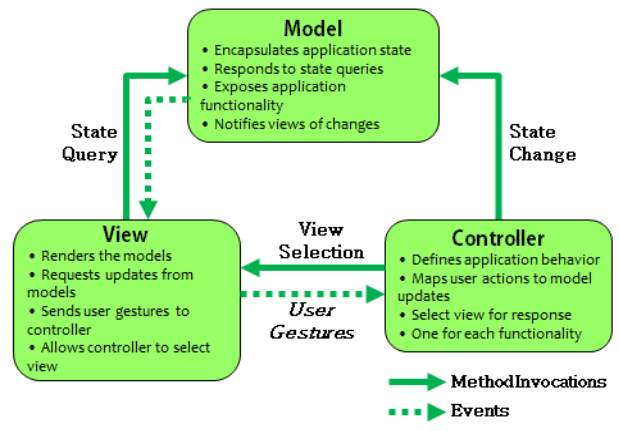

Figure 2. Architectural Model View Controller (MVC) 
a) Model: A representation of a database, including the design table to the relationships that exist between tables. The main function of the model is to handle the data,, retrieve data from the database, insert data into the database, data manipulation through data validation.

b ) View: View to render the given data model and will transmit motion/activity from the $\mathrm{u}$ consistency of data display to the changes that occur. By grouping all the display and presentation code in one place, will make it easy to change the look without affecting the business logic and data

c ) Controller : The controller defines the behavior that occurs in the application, and then mapping them into action from the user to the model. The controller will be very closely related to the View, because each user interaction to be performed will be shown by the View to a response by the Controller. In the controller there will be those methods that will respond to the behavior of the application .

\section{IMPLEMENTATION}

\section{A. Architecture CakePHP}

Below is a look at the website using CakePHP framework to display employee data.

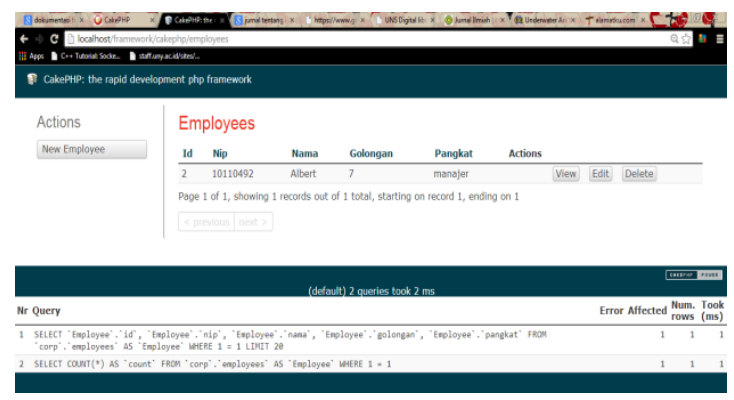

Figure 3. Pageviews Website Using CakePHP Framework

The script below shows that the var \$ name = 'Employee' will take a library of AppModel

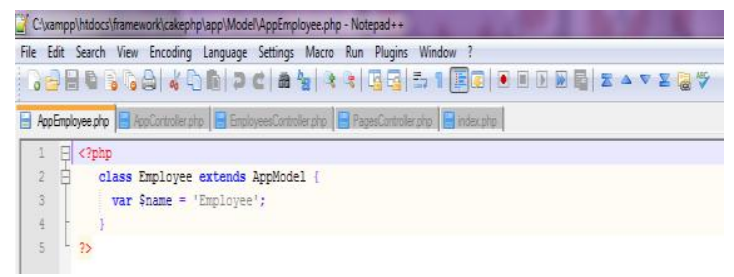

Figure 4. Scripts Models on AppModel.php

\section{B. Architecture CodeIgniter}

Making the main page on the website of the film with CodeIgniter framework is to create a view first. Then save it as movie.php. Enter into folders movie.php ujianweb / CI / application / views / movie. Here is a script that is contained in movie.php:

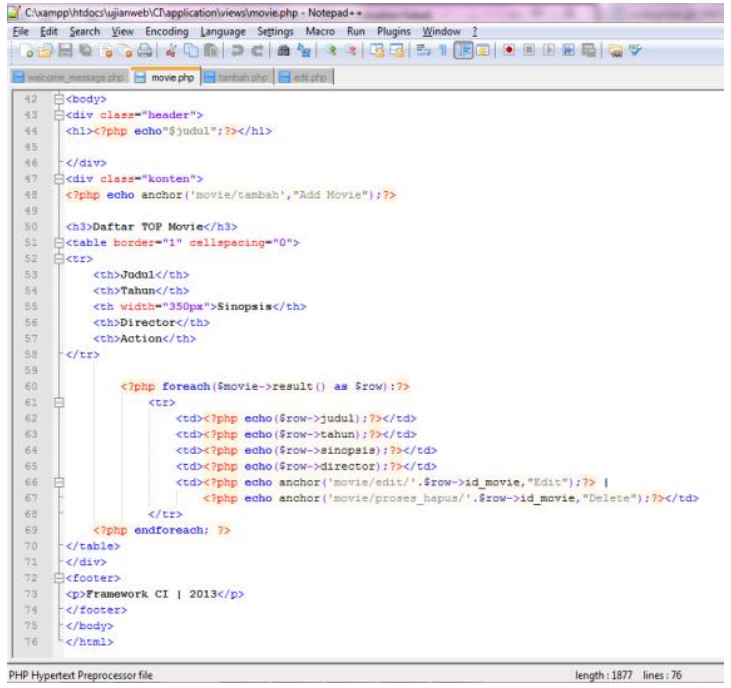

Figure 5. Scripts In Movie.php

The next step to create a file tambah.php add new button to add the latest movie data. The following script contained in plus.php:

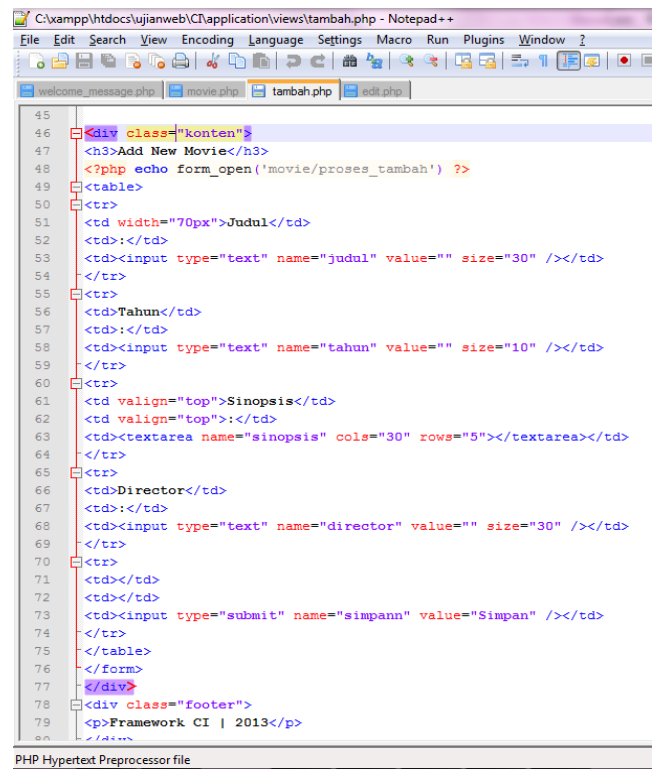

Figure 6. Scripts plus php

\section{COMPARATIVE ANALYSIS}

\section{Performance Aspect}

At this writing, to conduct performance testing of the performance of the local web server (localhost) that has been made is to use Apache Benchmark Software. The first request testing (Stress Testing Request) to the web using CodeIgniter framework by 1 users to localhost for 10 seconds. 


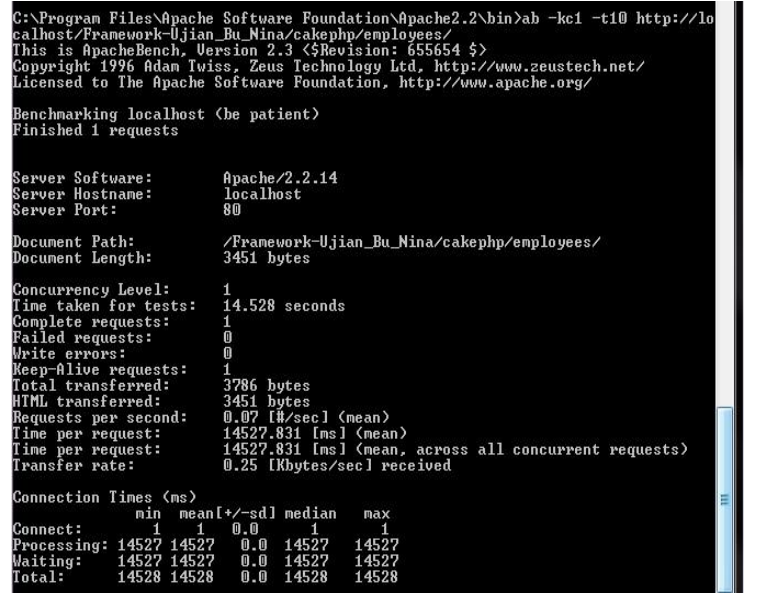

Figure 8. Testing Results Request To The Web Using CodeIgniter Framework

In figure 8 performed Connection Keep Alive representing 1 user $(-\mathrm{KC} 1)$ for 10 seconds (-t10). In 10 seconds can handle 303 requests (request) with an average rate of requests (Request per second) is 30.23 seconds and the rate of transfer (Transfer Rate) $63.37 \mathrm{Mb} / \mathrm{s}$.

Furthermore, the way the same test was also done on the web using CakePHP framework

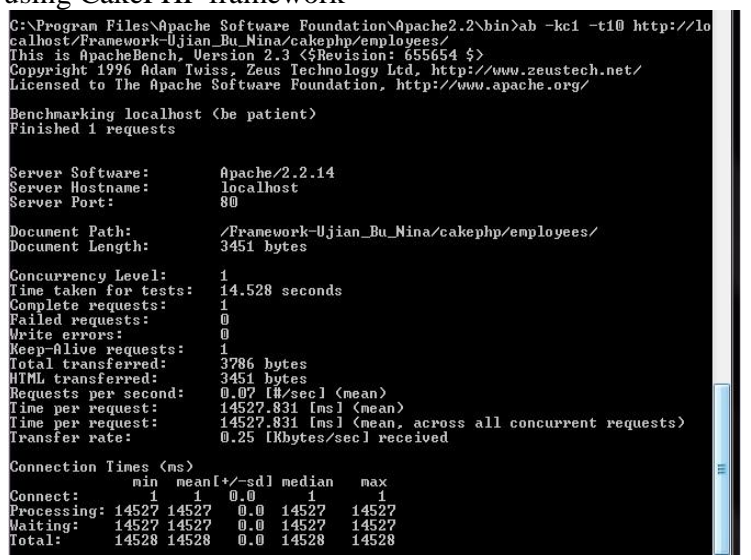

Figure 9. Testing Results Request To The Web Using CakePHP Framework

However, on the web using CakePHP framework (figure 9), in 14.528 seconds can only handle one request (request) with an average rate of requests (Request per second) is 0.07 seconds and the rate of transfer (Transfer Rate) $0,25 \mathrm{~Kb} / \mathrm{s}$. Further testing using one user who made 100 connections (KC1-N100) to the web using CodeIgniter framework.

Final testing is done in the same way, but by changing the total user time and time be-kc50-T120 (2 minutes).

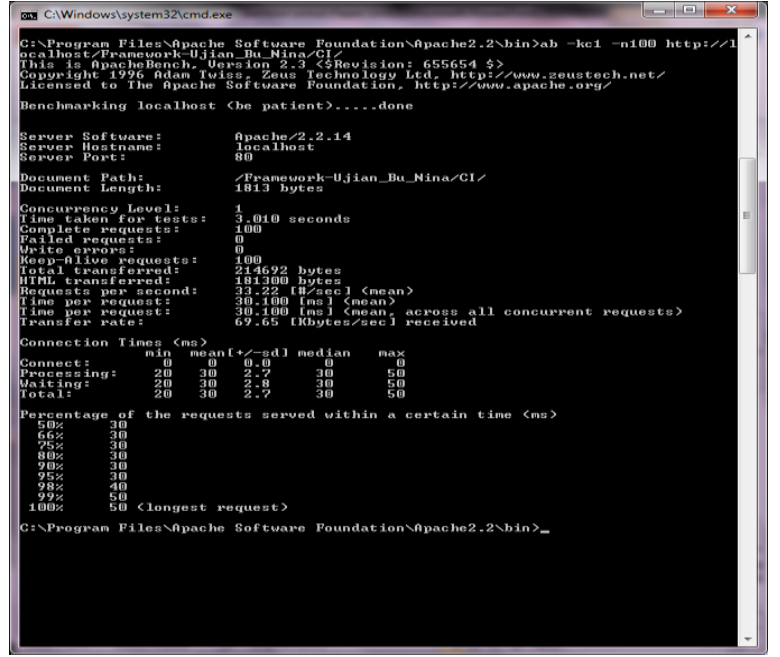

Figure 10. Results connected by 1 User Testing Against Web Using CodeIgniter Framework.

In figure 10 can be explained that the test for 3 seconds can handle 100 requests (Request) which represents one user at an average rate of requests (Request per second) is 33.22 seconds and the rate of transfer (Transfer Rate) $69.65 \mathrm{~Kb} /$ 's.

The same was done on the web using Cake PHP framework.

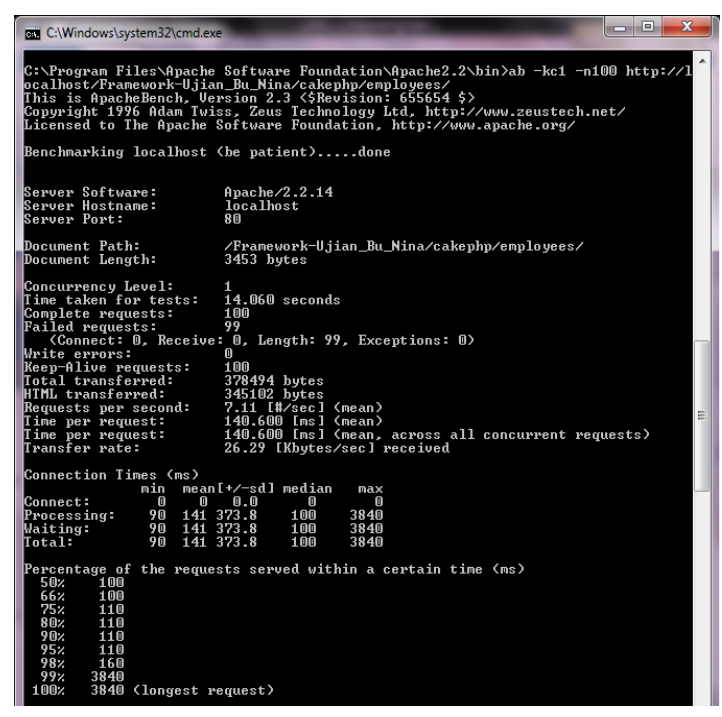

Figure 11. Results connected by 1 User Testing Against Web Using CakePHP Framework

Can be seen in figure 11 that the web using CakePHP framework has a longer processing time than the web using CodeIgniter framework, ie for 14 seconds. Do as many as 100 but the request failed (Failed Request) by 99 request. This means that within 14 seconds, CakePHP framework can only handle one request at an average rate of requests (Request per second) is 7.11 seconds and the rate of transfer (Transfer Rate) $26.29 \mathrm{Mb} / \mathrm{s}$.

Final testing is done in the same way, but by changing the total user time and time be-kc50-T120 (2 minutes). 


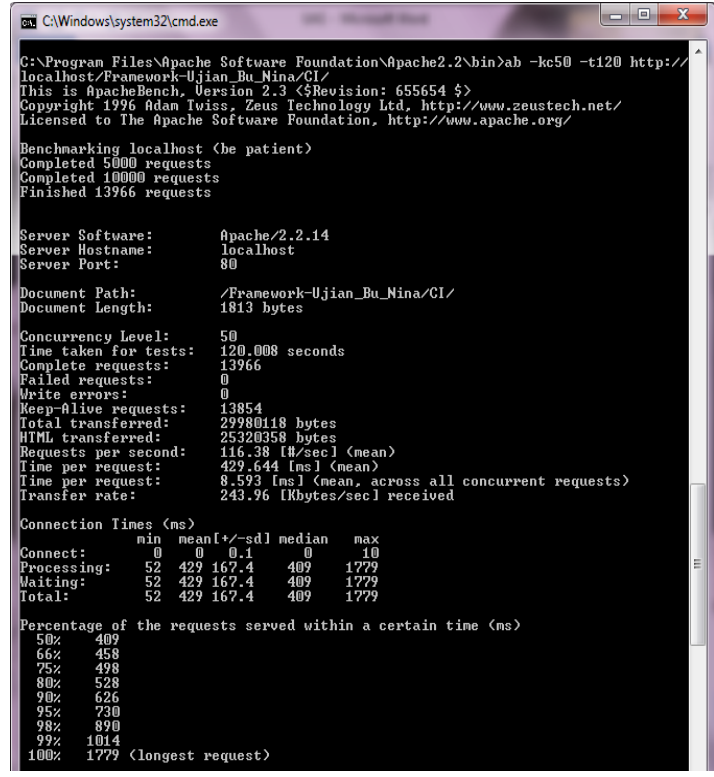

Figure 12. Testing Results Request by 50 Users Against Web Using CodeIgniter Framework

From Figure 12 can be explained that the test time for 120 seconds to handle 13966 requests (request) that represent 50 users with an average rate of requests (Request per second) was 116.38 seconds and the rate of transfer (Transfer Rate) $243.96 \mathrm{~Kb} / \mathrm{s}$. Furthermore, do the same thing to the web using the CakePHP framework.

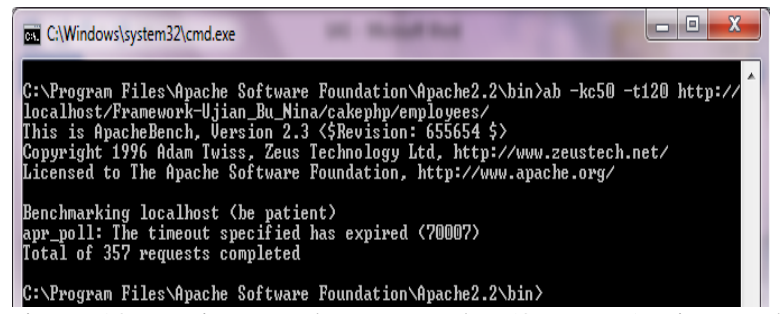

Figure 13. Testing Results Request by 50 Users Against Web Using CakePHP Framework

As shown in Figure 13, the web using CakePHP framework is only able to handle a total of 357 requests (request) within 120 seconds. However, in this test does not show the status of the Apache benchmark such as the testing that has been done before.

\section{Architecture}

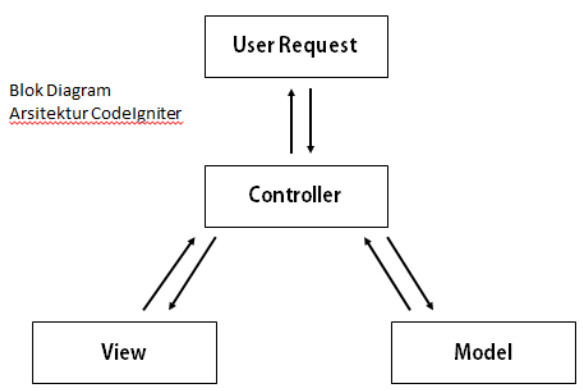

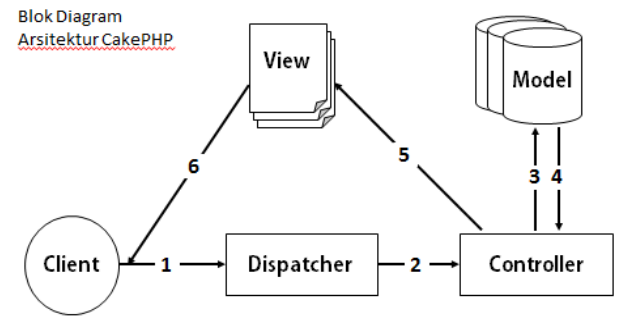

Figure 15. Features - features of CodeIgniter and CakePHP Framework

Description:

a) MVC: Indicates whether the framework is equipped with built-in support for setup Model-View-Controller. b) Multiple DB's: Indicates whether the framework supports multiple databases without the need to change anything.

c) ORM: Indicates whether the framework supports an objectroadmapper, which is usually an implementation of ActiveRecord.

d) DB Objects: Indicates whether the framework includes other database objects, such as TableGateWay.

e) Templates: Indicates whether the framework has a built-in template engine.

f) Caching: Indicates whether the object caching framework covers or other means for caching way.

g) Validation: Indicates whether the framework has a built-in validation or filter components.

h) Ajax: Indicates whether the framework is equipped with built-in support for Ajax.

E. ORM (Object Relational Mapping)

CodeIgniter does not support ORM (Object Relational Mapping) so that CodeIgniter does not support the implementation of the active record. While CakePHP ORM support of this work so that developers do not need to be mapped or her into a class mapping table, and the fields of the table becomes the property of the respective class. So when writing a program, no need to spend time writing queries, but simply call the class method as well as the usual coding. This feature is a huge time saver in creating web applications.

F. Size Library Framework

The size of the library on the second framework is only limited framework of $2 \mathrm{MB}$

\section{CONCLUSION}

In terms of features, Cake PHP provide more features than CodeIgniter. However, after a comparative analysis of both the framework in the creation of websites, I prefer to use CodeIgniter because lighter and easier to learn, modify, and integrate Library and Helper. However, it all comes back to the user any PHP framework, what kind suitable for use in the development of each of them based on the results of the analysis that has been done.

\section{ACKNOWLEDGMENTS}

Our thanks to Gunadarma University who sponsored this research.

\section{REFERENCES}

[1] (http://www.trenologi.com/201212066853/jumlahproyek-yang-ada-di-freelancerdotcom-telah-mencapai-4juta-proyek, Accessed on November 19,th, 2013). 
[2] (www.phpframeworks.com, diakses tanggal 19 November 2013)

[3] S. Safarudin, "Eksplorasi Yii Framework Sebagai Pendukung Pembuatan Software Berbasis Web (Studi Kasus Aplikasi Forum)," 2012.

[4] M. Michael, Choosing an Ajax Framework,[online], http://ajaxian.com/archives/choosing-an-ajaxframework

[5] P. Candra Adi, Ebook PHP vs CodeIgniter vs Yii Framework,[online], (www.candra.web.id).
[6] F.Martin, "UML Distilled: A Brief Guide to the Standard Object Modeling," Third Edition, USA, . Addison Wesley.

[7] D. Ibnu, "Ebook Framework Codeigniter: Sebuah Panduan dan Best Practice," 2011.

[8] G. Rajendra, Performance Testing for Ajax-based Applications[online], (http://itest.aztecsoft.com), 2007.

[9] (http://dee-xcisadane.webs.com/apps/blog/show/15213750-mengujiaplikasi-apache-2-xmenggunakan-apache-benchmark-ab,diakses tanggal 23 November 2013). 